\title{
Indian Medical Undergraduates' Perceptions of Effective Teaching Methods: A Cross-Sectional Study
}

\author{
Putul Mahanta $\mathbb{D}^{\prime}$ \\ Deepjyoti Kalita ${ }^{2}$ \\ Chiranjita Phukon ${ }^{3}$ \\ Ranjumoni Konwar ${ }^{4}$ \\ Kahua Das ${ }^{5}$ \\ Md Kalim Ullah ${ }^{6}$ \\ Dhirendra Singh Yadav ${ }^{7}$ \\ Sangeeta Deka ${ }^{2}$
}

'Department of Forensic Medicine and Toxicology, Assam Medical College and Hospital, Dibrugarh, Assam, India;

${ }^{2}$ Department of Microbiology, All India Institute of Medical Sciences, Rishikesh, Uttarakhand, India; ${ }^{3}$ Department of Medicine, Tezpur Medical College and Hospital, Tezpur, Assam, India; ${ }^{4}$ Department of Radiology, Fakhruddin Ali Ahmed Medical College and Hospital, Barpeta, Assam, India; ${ }^{5}$ Department of Physiology, Tezpur Medical College and Hospital, Tezpur, Assam, India;

${ }^{6}$ Department of Dentistry, Tezpur Medical College and Hospital, Tezpur, Assam, India; ${ }^{7}$ Central Forensic Science Laboratory, Directorate of Forensic Science Services, Ministry of Home Affairs, Government of India, Bhopal, India
Introduction: It becomes a challenge for a teacher to find a student-friendly approach to teach too many students in a class. The teaching methods used during medical education have a significant impact on learning among medical students. A practical and informative teaching technique is considered an essential component of that education. The present study aimed to determine the best interactive teaching method based on Indian medical undergraduates' perceptions.

Materials and Methods: The current investigation was a cross-sectional descriptive study that included 100 undergraduate medical students. A structured sample class on a specified topic was conducted using Microsoft PowerPoint (PPT) and a "chalk and talk" (CNT) method. Students' opinions of the class were assessed via a Likert scale questionnaire in which, for each of the two methods, the students were asked to rank twelve comments on a four-point scale: strongly agree, agree, disagree, or strongly disagree. Descriptive statistics were calculated to evaluate the distributions of their responses. The $\mathrm{z}$ test for two proportions was used to test a significant difference in respondents' proportions towards various perceptions regarding the two teaching methods under study. The data were analyzed using SPSS software version 22 .

Results: Students understood the lesson content better when the teacher used the CNT approach $(p<0.005)$. The CNT method was also associated with better interaction than the PPT technique $(p=0.03)$ and facilitated better student concentration and retention of the class content $(p=0.03)$. The students reported that there was less eye contact associated with the PPT technique $(61 \%)$ but found the content thus delivered fascinating (78\%), informative (91\%), and organized (85\%) as compared to the CNT approach.

Conclusion: The traditional CNT approach is an effective classroom teaching method. The current study highlights student preferences for a combined teaching method that includes CNT and PPT.

Keywords: classroom technique, medical education, student perspective, interactive teaching

\section{Introduction}

In recent decades classroom teaching methods have changed from the traditional CNT approach to the modern Microsoft PowerPoint (PPT) technique. Notably, however, which of the two is the best method can only be determined based on a better understanding of the lecture content by students.

In India, the National Medical Commission (NMC) comes into force, replacing the Medical Council of India (MCI) on 25.9.2020 with gazetted notification dated
Correspondence: Putul Mahanta

Department of Forensic Medicine and Toxicology, Assam Medical College and Hospital, Dibrugarh, Assam, 786002, India Tel +919435017802

Email drpmahanta@gmail.com 
24.9.2020. One of its objectives is to improve access to quality and affordable medical education to nearly $1,18,316$ medical graduates and 30,000 postgraduates yearly from 554 medical colleges across the country. ${ }^{1}$ Teaching such a vast number of students in different medical colleges are a difficult task for the teacher.

The educational environment perceived by students' influences satisfaction with their learning process and academic accomplishment. ${ }^{2}$ The classroom setting has significantly impacted the student's behavior, academic progress, and a sense of well-being. ${ }^{3-5}$

The lecture delivery is a dynamic procedure where both the teacher and student have to work reciprocally to make this process pleasant and more remarkable for understanding. ${ }^{6}$

In the existing system of teaching-learning method, some students find it challenging to opine about the teaching way of a teacher, whether his technique was straightforward one or merely, the approach was excellent. ${ }^{7}$

During classroom tuition, the visual and auditory senses are used to absorb information. The assistance of visual aids is beneficial. ${ }^{8}$ The use of transparencies and an overhead projector was historically a commonly utilized ${ }^{7}$ and well known ${ }^{9}$ means of classroom teaching. Chalkboards are one of the most common ${ }^{10}$ methods of the lecture delivery process.

Microsoft PowerPoint software developed by Robert Gaskins and Dennis Austin was released in 1987 and was purchased by Microsoft Corporation in the same year. PowerPoint facilitates visual demonstrations for group presentations and widely used in the lecture presentation. It also has wide applications in educational and community organizations. ${ }^{11}$ PPT helps the user to create a slide show of important information, charts, and images to display during a presentation with added features like subtitling on slides, slide transitions, background designs, animation, graphics, movie and sound clips, and Auto Content. ${ }^{11,12}$ PPT has recently become established as one of the most popular instructional aids, ${ }^{13-15}$ in conjunction with the computer becoming an unavoidable aid in modern-day classroom teaching. Nowadays, PPT has become the most common and straightforward method used by teachers to create classroom presentations, ${ }^{16}$ and millions of copies of the program are currently in circulation and used worldwide every day. ${ }^{17}$ Some surveys have been conducted to determine the usefulness of different teaching methods. The earlier CNT methods of lecturing were the methods most preferred by medical students in a study reported in $2007,{ }^{18}$ though PPT is now standard. ${ }^{16}$
Because of the above differences in preferences, the present study aimed to assess students' perceptions by comparing the PPT method with the traditional CNT approach. The study also seeks to find the best-suited way of teaching-learning to the needs of the Indian medical students from their perspective.

\section{Materials and Methods}

The present study was a cross-sectional descriptive survey that included 100 undergraduate 4th-semester MBBS students of Assam Medical College and Hospital, Dibrugarh, Assam, India, from October 2020 to February 2021. The study participants were selected using a simple random sampling method. A semi-structured questionnaire was used to collect information about the students' likings and observations regarding the theory class's teaching-learning approach. A structured sample class on a predetermined lecture topic was delivered using PPT and CNT, and students' perceptions were ascertained via a Likert scale questionnaire. For each of the two methods, the students were asked to rank twelve comments on a four-point scale: strongly agree, agree, disagree, or strongly disagree. Each student was asked to mark their responses in two different questionnaires on the two different teaching methods (Table 1).

Table I Statements Regarding the Perception of the Two Teaching Methods

\begin{tabular}{|l|l|}
\hline $\begin{array}{l}\text { Question } \\
\text { No. }\end{array}$ & Statements Regarding Perception \\
\hline Q1 & $\begin{array}{l}\text { I understand the lecture better when the teacher uses } \\
\text { this technique }\end{array}$ \\
\hline Q2 & I feel the student interaction is better with the teacher \\
\hline Q3 & Eye contact between teacher and student is less \\
\hline Q4 & The lecture advances the understanding \\
\hline Q5 & $\begin{array}{l}\text { This technique helps me to concentrate and } \\
\text { remember better }\end{array}$ \\
\hline Q6 & $\begin{array}{l}\text { The quality and quantity of my lecture notes cannot be } \\
\text { maintained }\end{array}$ \\
\hline Q7 & The delivery of the lecture is interesting \\
\hline Q8 & The content of the lecture informative \\
\hline Q9 & The lecture is audible \\
\hline Q10 & The lecture content was well organized \\
\hline Q11 & The teacher remains more professional \\
\hline Q12 & The teacher needs more preparation for the class \\
\hline
\end{tabular}


Thus, further analysis in the present study was done with a total of 200 questionnaires. The validity and reliability of the questionnaire were tested using appropriate methods. The questionnaire's reliability in assessing the perceptions on the chalk and talk method of teaching was found to be reasonably good (Cronbach's Alpha 0.85), and that for PPT was excellent (Cronbach's Alpha 0.9).

Statistical analyses to determine whether there were any significant differences between responses towards a particular perception about the two methods was done using the $\mathrm{z}$ test for two proportions and were performed using Microsoft Excel (Microsoft Corporation, Redmond, WA) and the Statistical Package for the Social Studies (SPSS) version 22 (IBM Corp., Armonk, New York). A p-value $<0.05$ was considered to be significant.

Participants' individual identities were not revealed throughout the study, so approval was not required from the institutional ethics committee. However, ethical approval was sought from Assam Medical College and Hospital's ethics committee, Dibrugarh, Assam, which was approved vide Ref: AMC/EC/4299. Nonetheless, all students provided informed consent prior to the collection of the data.

\section{Results}

The age of the participants ranged from 22 to 23 years. Out of the 100 study participants, 57 were male, and 43 were females.

The distributions of "strongly agree" responses with respect to various perceptions are shown in Figure 1. A relatively higher proportion of the students (30\%) strongly agreed that they understood the lecture content better when it was delivered via PPT. However, more students agreed that the CNT method was better than the PPT method with regard to student-teacher interaction (33\% vs 29\%).
A more significant proportion of the students (38\%) strongly agreed that the CNT method was more conducive to concentration and content retention than PPT (30\%). There was also strong agreement that the CNT method fostered interest (26\%) and was sufficiently audible (28\%). Notably, however, compared to the CNT method, more students thought that PPT was superior with respect to the content organization $(35 \%$ vs $30 \%)$, professionalism $(27 \%$ vs $25 \%)$, and preparation (31\% vs $30 \%)$.

The distributions of "agree" responses with respect to various perceptions are shown in Figure 2. The majority favored CNT over PPT with respect to better understanding the lecture (71\% vs $56 \%)$ and better interaction with the teacher ( $53 \%$ vs $45 \%)$. CNT was also rated better than PPT with regard to concentration and content retention $(50 \%$ vs $46 \%$ ), as well perceptions of teacher professionalism (59\% vs $52 \%$ ) and preparation. To the suggestion that PPT was associated with a lack of eye contact between the teacher and students, $47 \%$ responded with "agree", compared to $41 \%$ for CNT. PPT attracted more "agree" responses than CNT with respect to being an attractive (58\% vs $51 \%)$ and informative ( $71 \%$ vs $68 \%$ ) teaching modality.

The distributions of "disagree" responses with respect to various perceptions are shown in Figure 3. Among the 100 study participants, $12 \%$ disagreed that PPT was a better teaching model for students' understanding, and $24 \%$ disagreed that teacher-student interaction is better in PPT. More respondents disagreed with the suggestions that PPT advances understanding of lecture content (16\% vs $12 \%)$, facilitates better concentration and content retention $(21 \%$ vs $10 \%)$, is audible $(12 \%$ vs $17 \%)$, that the teacher is more professional (20\% vs $15 \%)$, and that the PPT lecture would take the teacher a lot longer than preparing a CNT lecture ( $23 \%$ vs $18 \%$ ). Notably, however, $20 \%$ of the respondents

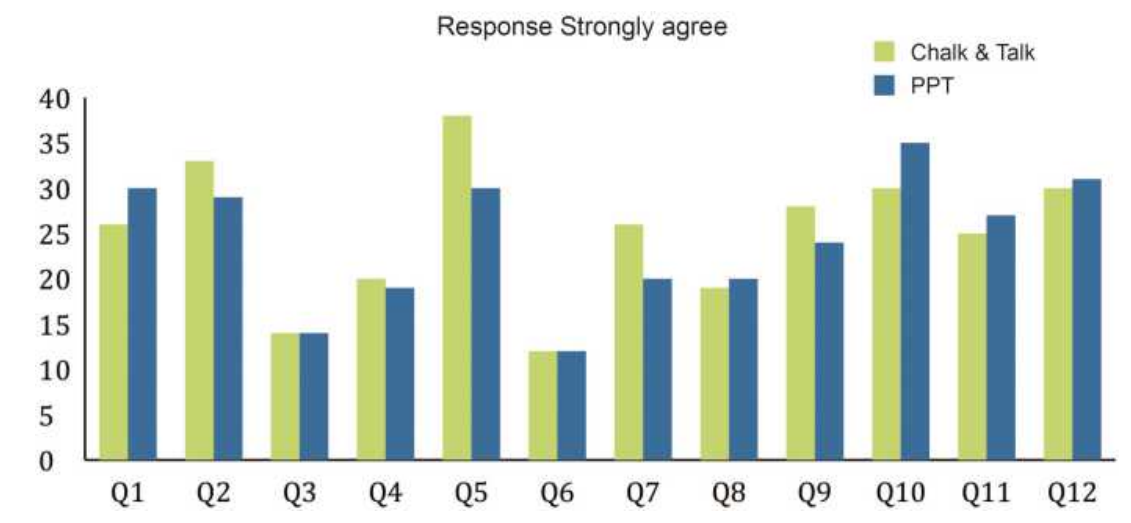

Figure I Pattern of "strongly agree" responses to various survey prompts (PPT-PowerPoint). 


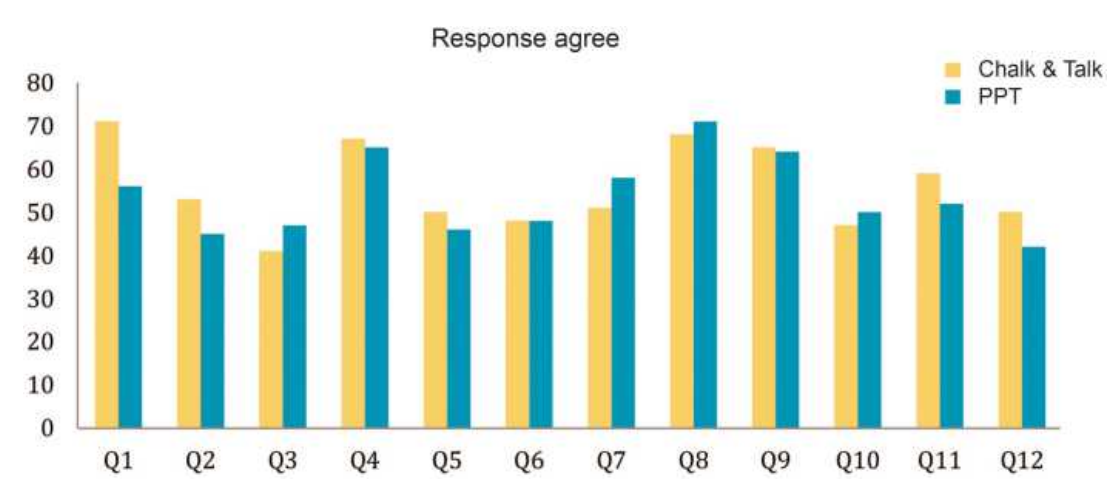

Figure 2 Pattern of "agree" responses to various survey prompts (PPT-PowerPoint).

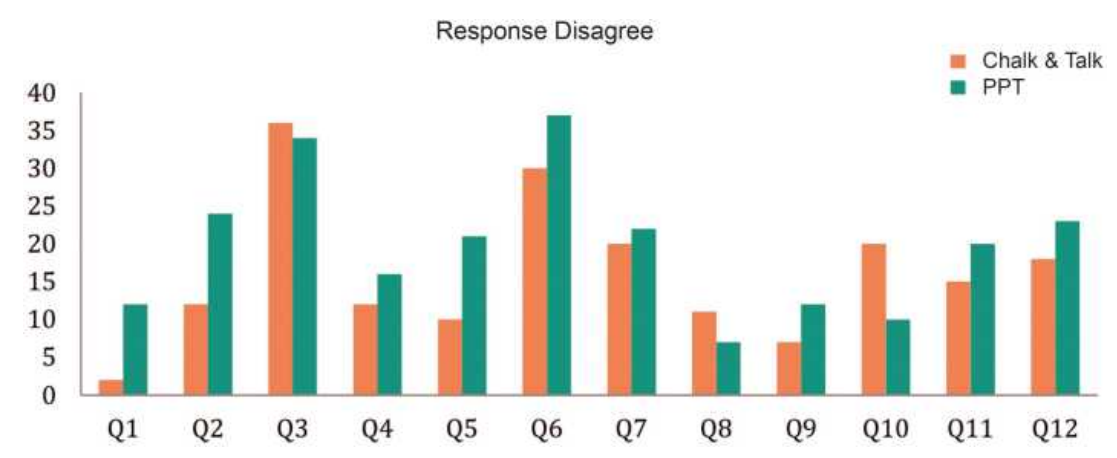

Figure 3 Pattern of "disagree" responses to various survey prompts (PPT-PowerPoint).

disagreed that the CNT method is well organized. Small numbers of respondents strongly disagreed that there was a lack of eye contact between teacher and student associated with CNT (9\%) and PPT (5\%) and that the quality and quantity of the lecture notes could not be maintained with respect to CNT (10\%) and PPT (3\%), as shown in Figure 4.

In our present study, the study participants' responses on the 12 statements regarding their perceptions were collected separately for each of the teaching methods in two different questionnaires implying a total of 200 questionnaires and thus with a possibility of agreeing or disagreeing with any of the perceptions for one or both the methods. We have used the $\mathrm{z}$ test for two proportions to test whether there are any significant differences in proportions of responses towards the perceptions under study between the two teaching methods.

The total number of study participants who agreed with a particular perception was assessed by summing up the number of responses "strongly agree" and "agree" for that specific perception. Similarly, the number of responses "disagree" and "strongly disagree" for a particular perception was summed up to evaluate the total number of

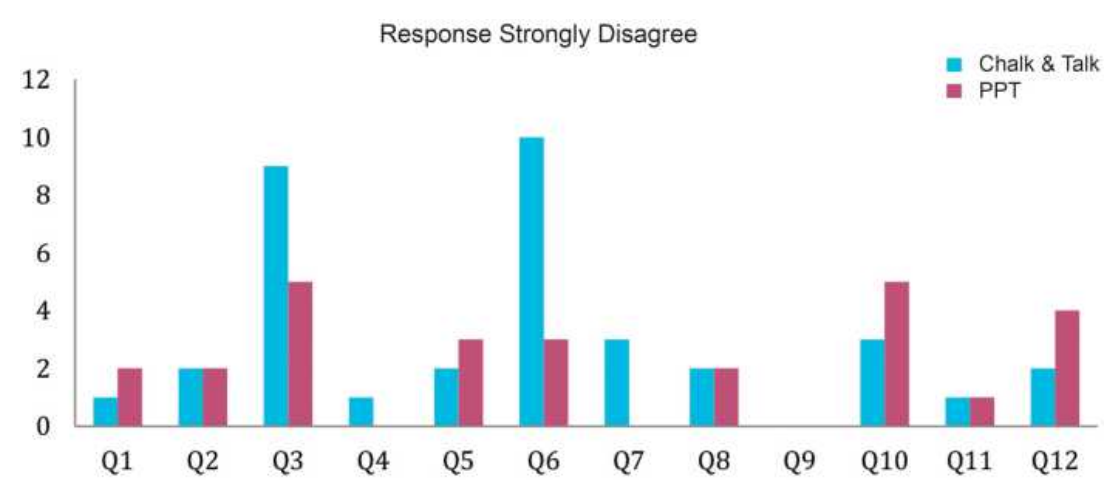

Figure 4 Pattern of "strongly disagree" responses to various survey points (PPT-PowerPoint). 
disagreements for that perception. The proportion of respondents that favored CNT (97\%) as a method that facilitated better understanding was significantly higher than the proportion that favored PPT (86\%). Eighty-six percent of the respondents agreed that CNT fostered better student-teacher interaction than PPT $(p<0.05)$, and $88 \%$ agreed that CNT helped them to concentrate and remember the course content better $(p<0.05)$. There were no significant differences in respondents' proportions in broad agreement with other perceptions evaluated in the study (Table 2).

\section{Discussion}

The current study investigated student perceptions in an effort to identify the lecture delivery techniques they favored in the classroom. There was a strong agreement that the CNT method is a better technique than PPT with respect to promoting concentration and content retention. This is concordant with a previously reported review. ${ }^{19}$ The CNT method of teaching allows the students to note the teacher's talk comfortably, but doing the same with a PPT lecture is not as easy due to the comparative rapidity of delivery.

PPT lectures were deemed more attractive, informative, and well organized by the students in the current study. This may be due to the absence of three-dimensional figures, animated videos, and real-time sounds associated with the CNT method. The inclusion of such features in PPT presentations can help enhance student satisfaction.

In the present study, the respondents significantly preferred lecture delivery in CNT as a clear and understandable method. Also, to concentrate and remember the content, higher proportions of respondents agreed on CNT as a helpful technique compared to PPT. The CNT method remained a dominant form of lecture delivery and was preferred by the students in a review reported in $2010,{ }^{20}$ consistent with the current findings. However, the students felt that the lecture contents were more informative when delivered via PPT compared to the CNT method. PPT slides facilitate lecture delivery with numbers, figures or new concepts via visual aids, which helps in providing more information in less time. ${ }^{8}$

No significant differences in reported perceptions of CNT and PPT methods were evident in the current study with respect to teacher-student eye contact, advancing student understanding, maintaining the quality and quantity of lecture notes, generating interest, informative content, audibility or professionalism of the teacher. These findings are consistent with some other studies. ${ }^{21,22}$ In another study, most participants, advocated a combined method ${ }^{23}$ of teaching, which is concordant with the current study results as in the present study, none between two teaching methods were opined to be the single best method of lecture delivery.

In the present study, student ratings of the teacher's professional responses did not differ significantly between the two methods. Although the development of modern technology has provided various up to date and advanced ways of displaying and delivering lecturers in the classroom, however, the essential aspect of any teaching method is the teacher himself. The teacher must be knowledgeable and has to be well versed with the topic to make students understand and develop interest. The importance of the teacher's quality, irrespective of the methods they used in the classroom were

Table 2 Difference in Proportions of the Agreement for Various Perceptions Towards the Teaching Methods Understudy

\begin{tabular}{|l|l|l|l|l|l|}
\hline $\begin{array}{l}\text { Question } \\
\text { No. }\end{array}$ & \multicolumn{2}{|l|}{ Proportions of Agreement } & \multicolumn{2}{l|}{$\begin{array}{l}\text { Chi-Square } \\
\text { (p-value) }\end{array}$} & \multicolumn{2}{l|}{ Proportions of Disagreement } \\
\cline { 2 - 6 } & Chalk and Talk (CNT) & $\begin{array}{l}\text { PowerPoint } \\
\text { (PPT) }\end{array}$ & & Chalk and Talk (CNT) & $\begin{array}{l}\text { PowerPoint } \\
\text { (PPT) }\end{array}$ \\
\hline Q1 & 97 & 86 & $7.74(0.005)^{* *}$ & 3 & 14 \\
Q2 & 86 & 74 & $4.47(0.03)^{*}$ & 14 & 26 \\
Q3 & 55 & 61 & $0.73(0.39)$ & 45 & 39 \\
Q4 & 87 & 84 & $0.36(0.54)$ & 13 & 16 \\
Q5 & 88 & 76 & $4.85(0.03)^{*}$ & 12 & 24 \\
Q6 & 60 & 60 & - & 40 & 40 \\
Q7 & 77 & 78 & $0.03(0.86)$ & 23 & 22 \\
Q8 & 87 & 91 & $0.81(0.37)$ & 13 & 9 \\
Q9 & 93 & 88 & $1.45(0.23)$ & 7 & 12 \\
Q10 & 77 & 85 & $2.07(0.15)$ & 23 & 15 \\
Q11 & 84 & 79 & $0.82(0.36)$ & 16 & 21 \\
Q12 & 80 & 73 & $1.36(0.24)$ & 20 & 27 \\
\hline
\end{tabular}

Notes: *p-value is significant, ${ }^{* *} \mathrm{p}$-value is highly significant. 
emphasized by Ahmed $\mathrm{C}$ in his research report almost two decades ago, which is relevant in present times also. ${ }^{24}$ In another study comparing electronic presentations versus CNT, the authors advocated that the quality of the teacher is more vital than the teaching method he adopts as a good quality teacher knows how to impart essential information that students find accessible, which can prepare them to understand newer and more challenging things irrespective of the teaching method used. ${ }^{25}$

\section{Limitations}

The present study was conducted in only one medical institution, including the 4th-semester undergraduate MBBS students. It limits the study results to come to an overall conclusion about the medical students' perception of the teaching methods. Inclusion of more similar institutions and students of postgraduate or other undergraduate MBBS programs may enable the researchers to have a more generalized conclusion about the teaching methods' perceptions and limitations.

\section{Conclusion}

The study highlights a preference for a combined teaching method that includes both CNT and PPT. However, most of the present study participants emphasized the importance of CNT, acknowledged it as an effective and convenient teaching modality, and recommended it for teaching. The study clearly indicates the benefits of the conventional CNT method with regard to better understanding and learning the concepts presented.

\section{Ethics Considerations}

All data were treated confidentially, and the study was conducted in accordance with the Declaration of Helsinki.

\section{Acknowledgments}

Thanks to the student participants who have participated in this study and have given their valued responses. All departmental colleagues who helped us access the departmental library and settings during the study were also acknowledged.

\section{Author Contributions}

All authors made a significant contribution to the work reported, whether that is in the conception, study design, execution, acquisition of data, analysis and interpretation, or in all these areas; took part in drafting, revising or critically reviewing the article; gave final approval of the version to be published; have agreed on the journal to which the article has been submitted; and agree to be accountable for all aspects of the work.

\section{Funding}

There is no funding to report.

\section{Disclosure}

The authors report that there are no conflicts of interest pertaining to this work.

\section{References}

1. National Medical Commission. Mission and vision. 2020 [cited March 20, 2021]; Available from: https://www.nmc.org.in/aboutnmc. Accessed May 7, 2021.

2. Amaranathan A, Dharanipragada K, Lakshminarayanan S. Medical students' perception of the educational environment in a tertiary care teaching hospital in India. Natl Med J India. 2018;31(4):231-236. doi:10.4103/0970-258X.258226

3. Preethi GP, Menezes V, Srikanth AMS, Jnaneshwara PS. Medical students' perception of their educational environment. J Clin Diagn Res. 2014;8(1):103-107. doi:10.7860/JCDR/2014/5559.3944

4. Nor Iza AR, Aniza AA, Zulkifli Z, et al. Perceptions of students in different phases of medical education of the educational environment: University Sultan Zainal Abidin. Adv Med Educ Pract. 2015;6:211-222. doi:10.2147/AMEP.S78838

5. Xin X, Daxing W, Zhao X, et al. Relation of perceptions of educational environment with mindfulness among Chinese medical students: a longitudinal study. Med Educ. 2016;21:30664. doi:10.3402/ meo.v21.30664

6. Papanna KM, Kulkarni V, Tanvi D, et al. Perceptions and preferences of medical students regarding teaching methods in a Medical College, Mangalore, India. Afr Health Sci. 2013;13(3):808-813. doi:10.4314/ ahs.v13i3.41

7. Mishra H, Kumar V, Modi PK. Comparison of different teaching methodologies in a medical college in North India. IJBAMR. 2013;2(6):464-469.

8. Sahu DR, Supe AN. The art and science of presentation: $35-\mathrm{mm}$ slides. J Postgrad Med. 2000;46(4):280-285.

9. Estes A, Ressler S, Welch R, Hanus J. Seminar on communication skills. Exceed Teaching Workshop 2009. [cited December 30, 2020]. Available from: https://slideplayer.com/slide/2509710/. Accessed May 7, 2021.

10. Yao JE, Ouyang JR, Wang H. A farewell to the traditional instructional media and technologies in the new millennium. 2000 [cited December 30, 2020]. Available from: https://files.eric.ed.gov/fulltext/ ED444466.pdf. Accessed May 7, 2021.

11. Britannica, The Editors of Encyclopaedia. Microsoft PowerPoint. Encyclopedia Britannica. 2019; [cited January 21, 2021]; Available from: https://www.britannica.com/technology/Microsoft-PowerPoint. Accessed May 7, 2021.

12. Introduction to PowerPoint [Online]. Microsoft educator center. 2021. [cited March 21, 2021]. Available from: https://education.micro soft.com/en-us/resource/a2500c7b. Accessed May 7, 2021.

13. Prasad S, Roy B, Smith M. The art and science of presentation: electronic presentations. J Postgrad Med. 2000;46:193-198.

14. Ljungdahl RT. Technology Integration in the Teacher Preparation Program and Public Schools in Sam Houston Center for Professional Development and Educational Partnerships at Sam Houston State University. Vol. 9982142. ProQuest Dissertations Publishing;2000. [cited December 30, 2020]. Available from: https://www.proquest. com/docview/304646682. Accessed May 7, 2021. 
15. Ankad RB, Shashikala GV, Herur A, Manjula R, Chinagudi S, Patil S. PowerPoint presentation in learning physiology by undergraduates with different learning styles. Adv Physiol Educ. 2015;39 (4):367-371. doi:10.1152/advan.00119.2015

16. Pedras MJ, Horton J. Using technology to enhance teacher preparation. Paper presented at the Northwest Association of Teacher Educators Annual Conference 1996. [cited February 2, 2021]. Available from: http://files.eric.ed.gov/fulltext/ED395929.pdf. Accessed May 7, 2021.

17. Arriesgado A. Everything you need to know about PPT: what is a PowerPoint presentation, and how do you create one? [Internet]. Present better. March, 2018. [cited December 30, 2020]; Available from: https://24slides.com/presentbetter/what-is-powerpointpresentation/. Accessed May 7, 2021.

18. Novelli Ethel LB, Fernandes Ana AH. Students' preferred teaching techniques for biochemistry in biomedicine and medicine courses. Biochem Mol Biol Educ. 2007;35(4):263-266. doi:10.1002/bmb.73

19. Seth V, Upadhyaya P, Ahmad M, Kumar V. Impact of various lecture delivery methods in pharmacology. EXCLI J. 2010;9:96-101.

20. Seth V, Upadhyaya P, Ahmad M, Kumar V. An assessment of teachers' preference for lecture delivery methods in medical education. Educ Res Rev. 2010;5(9):533-537.
21. Baxi SN, Shah CJ, Parmar RD, Parmar D, Tripathi CB. Students' perception of different teaching aids in a medical college. AJHPE. 2009;1(1):15-16.

22. Vikas S, Prerna U, Mushtaq A, Vijay M. PowerPoint or chalk and talk: perceptions of medical students versus dental students in a medical college in India. Adv Med Educ Pract. 2010;1:11-16. doi:10.2147/AMEP.S12154

23. Chaudry R, Dullo P, Gupta U. Attitude of 1st MBBS medical students about two different visual aids in physiology lectures. Pak J Physiol. 2009;5(2):94-96.

24. Ahmed C. PowerPoint versus traditional overheads: which is more effective for learning? Conference for the South Dakota Association for Health, Physical Education and Recreation. 1998 [cited December 30, 2020]. Available from: https://files.eric.ed.gov/full text/ED429037.pdf. Accessed May 7, 2021.

25. Shallcross DE, Harrison TG. Lectures: electronic presentations versus CNT- a chemist's view. Chem Educ Res Pract. 2007;8:73-79. doi:10.1039/B6RP90021F

\section{Publish your work in this journal}

Advances in Medical Education and Practice is an international, peerreviewed, open access journal that aims to present and publish research on Medical Education covering medical, dental, nursing and allied health care professional education. The journal covers undergraduate education, postgraduate training and continuing medical education including emerging trends and innovative models linking education, research, and health care services. The manuscript management system is completely online and includes a very quick and fair peer-review system. Visit http://www.dovepress.com/testimonials.php to read real quotes from published authors. 